\title{
The Rocky Mountain Spartans
}

Cite as: CMAJ 2020 March 30;192:E347-8. doi: 10.1503/cmaj.190701

can't say I recognized him at first, faltering as he stood to wipe mud from his eyes and choking on anguished breaths. But then again my eyes were still clouded from the icy sludge we had both been immersed in, and my bloodied elbow competed for my attention in the frigid mountain air. As Chris, my physician colleague with his penchant for tormentous adventures, came into focus he offered his usual wry smile and a steady hand. The other Tragically Unfit Mamma's Boys, our team's moniker in this Spartan endurance race high in the Rocky Mountains, were waiting ahead. Together, my teammates and fellow rural family physicians had trained for the past year to share in this revelry of self-abuse. This was our first Spartan competition, a gruelling combination of distance running over mixed terrain with obstacle stations. We reunited and laughed in muddied solidarity. We were well on our way to becoming Spartans.

It wasn't always like this. Acerbic words between neighbouring regional medical staffs were indicative of stress and emerging burnout - myself included. But Bart, straddling both worlds as a rural emergency department physician, aspired for something better. I enjoyed many a long late-night discussion with Bart in the hidden corridors of our rural hospital. He was a bear of a man who repressed tears for everything he had internalized over the years, yet he was also a gentle soul carrying the weight of his profession and always willing to take on more if it would help a colleague. It helped me.

The solution, as Bart saw it, was found in poker. Monthly poker nights forced our hands from one-of-a-kind to the full house of an emerging den of friendships among work-weary physicians. I could go on butchering poker metaphors, but instead I will just state: poker night was never really about cards. We granted one

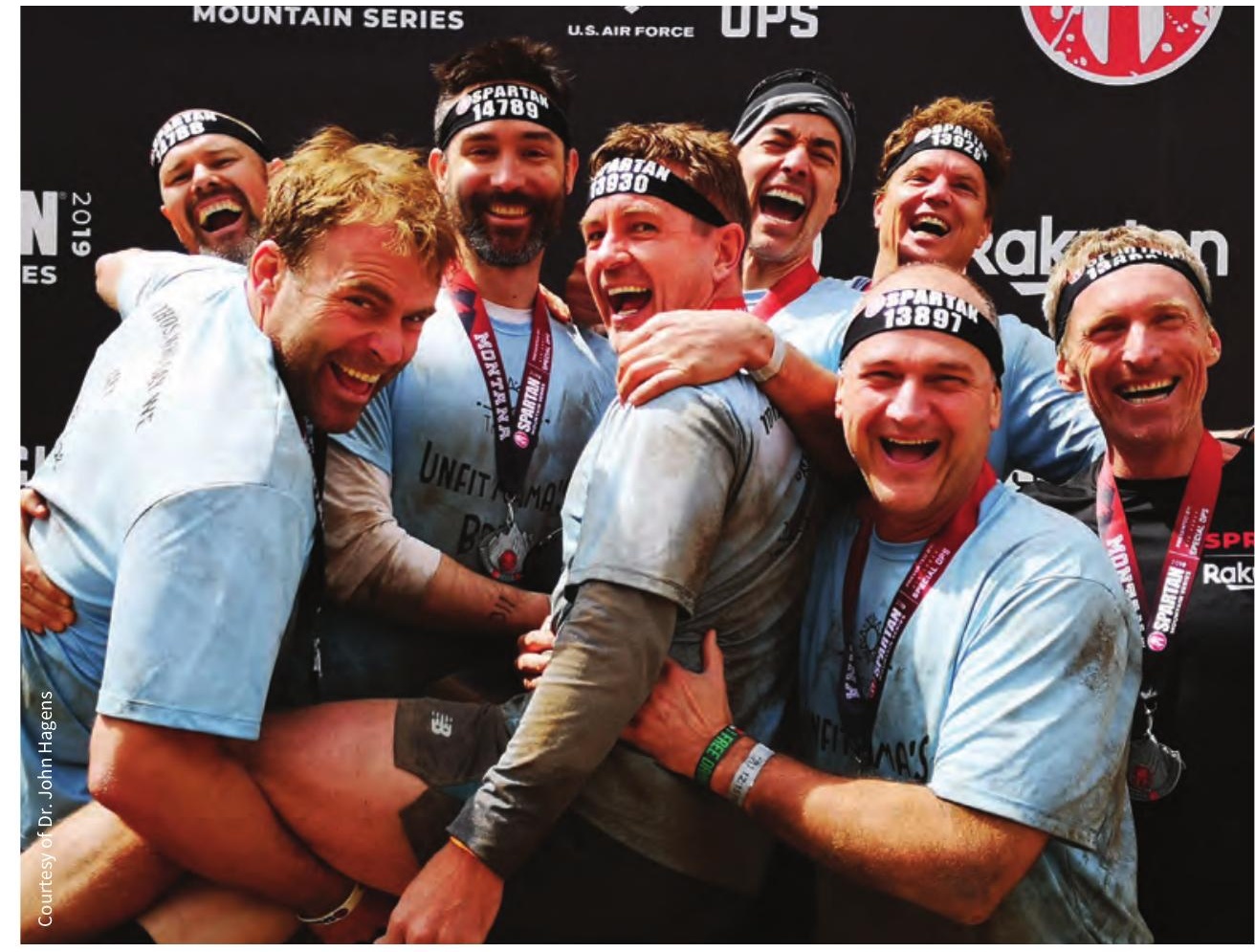

The Tragically Unfit Mamma's Boys (left to right): Chris Warner, Chris Powell, Tristan Hembroff, Anton Nel, Kevin Walsh, Christo Rabie, John Hagens and Steve Finnegan. Absent: Steve Douglas.

another amnesty from our usual ornery medical selves as we lost token sums and won them again while collegially considering our lives over good food and wine. I will add that this cobble of country doctors are not only good men, but the best of men: leaders in life who care for their families and patients to the point where the need to impose boundaries between their medical and social selves became evident. They know that the irrevocable blurring of these dual personas could create malignant infirmities in each. The literature here is clear: optimizing outcomes for patient care and medical career fulfilment are in part predicated upon "collaboration with others while maintaining one's core identity and values ... ." In medicine, we all need some supportive professional camaraderie.
You may perhaps understand the pain I feel in writing this even now, more than two years after Bart's death. Perhaps I should have listened more; this thought has never left me. We eventually came to understand why he chose the night of our medical staff meeting, when no one would be around to just drop in. Some questions were answered, but the rest were left for us to bury forever. We mourned Bart's death in our individual ways but also collectively. We came to see physician suicide in a more personal light and committed ourselves to taking better care of each other in his memory. We resumed our poker nights and shared our stories, while also creating new communal events like our Spartan Race. Bart probably would have cursed us for dragging him along, bellowing on about the 
lack of visible automatic external defibrillators on the trails ahead, but he would have been there, heckling and straining along with all of us through the boulderstrewn hills and clay-slicked obstacles. Through his memory, we became Spartans together. Participating in this endurance team race is the physical equivalent of the fraught medical lives we often live, but unlike our work setting, it has brought a more conscious, visceral awareness of our interdependence on each other.

The noble attributes that brought us all into medicine have proven to be our very liabilities: perfectionism, sensitivity to the needs of others, impossible work ethics. The culture of medicine is partly responsible for the creation of the "wounded healer.",3 And the stakes are high. Among all occupations, the medical profession consistently ranks near the top for risk of death by suicide. ${ }^{4}$ The risk among male physicians is 1.41 times higher than the general male population and 2.27 times higher for female physicians. ${ }^{5}$ Meanwhile, burnout hovers around $30 \%$ among Canadian physicians. ${ }^{6}$

Professional isolation has become more commonplace, rendering interpersonal collegial connections even more important. ${ }^{7}$ Yet medical staff rooms places of social connection and collaboration - are disappearing. Would a return to early morning clinical chats with colleagues over coffee help our professional days glow brighter? Would they, by extension, imbue our personal lives with more meaning? Is the solitary nature of modern communications keeping us in social quarantine; our lonely text messages forever nipping at our souls? Might we also consider whether our pain is self-inflicted, the repercussion of striving to hold too tightly to these slowly eroding facades of forbearance and personal fortitude? Physicians often move on seemingly undeterred, projecting strength to the infirm and to each other. For some of us, feelings are inappropriately internalized, often imperceptibly to us, although lucidly transparent to our families. Again, questions remain.

I've seen my days of death and suffering and it's changed me, as it should the dispassionate nature of illness is not without its dehumanizing influence. But some days, like some philosophical

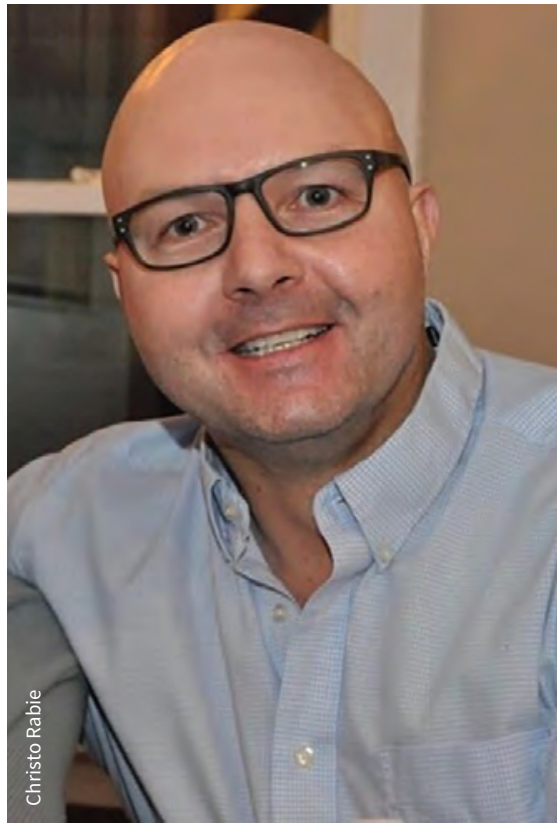

Bartholomeus Lombard.

punch in the gut, we still ache long after our patients have left us. For isn't silently managing these stresses what is often expected of us as physicians? Aren't we expected to display resilience despite the disquietude that often permeates our professional lives - weighted as they are under the sufferings of our patients?

So here we are, Spartans all. The last of the mud and clay are finally gone from our various orifices, our physical bruises have faded, but some unseen injuries will remain forever. After Bart's death, we planted a tree, affectionately dubbed "Maple-Bart." The deer necessitated replacing it with Maple-Bart 2.0, followed by a half-chewed new elderberry. But we continue to stand in tribute, undeterred.

Life is hard, practising medicine is exacting, and taking tangible steps to be our brothers' keepers is perhaps most exigent to the busy lives we keep. And yet, this is essential. Medicine often selects to be seated within its hallowed halls those most willing to forego themselves for the sake of others. We need each other to remind us when the cost is too high. For the pain of self-suffering is also injury. Research has found that preserving our humanistic approaches to patient care prevents burnout. ${ }^{3}$ Furthermore, when physicians identified "the external environment as an important factor in fostering humanism. They cited supportive colleagues and supportive systems, both of which facilitate engagement and connection with their patients." 3 Even here, caution is required. While extending our empathy to our peers, we must also respect that old dictum to "first do no harm" to the unintended neglect of the weight of our own burdens. We need to strive towards this delicate, yet ever necessary balance.

Bart expected us to be better colleagues, and because of this we will also be more attentive partners, more collaborative health providers and gentler with ourselves in our professional self-expectations. Although the mountains' trails be at times dark and unsteady, we'll remain Spartans together, holding each other steady as Bart once exemplified for us.

\section{John Hagens MD}

Calgary, Alta.

\section{References}

1. Branch WT, Weil AB, Gilligan MAC, et al. How physicians draw satisfaction and overcome barriers in their practices: "It sustains me". Patient Educ Couns 2017;100:2320-30.

2. Myers MF. Why physicians die by suicide: lessons learned from their families and others who cared. Michael F. Myers [publisher]; 2017.

3. Chou CM, Kellom K, Shea JA. Attitudes and habits of highly humanistic physicians. Acad Med 2014; 89:1252-8.

4. Andrew L, Brenner B. Physician suicide. Medscape; updated 2018 Aug. 1. Available: https://emedicine .medscape.com/article/806779-overview (accessed 2018 May 23).

5. Healthcare professional burnout, depression and suicide prevention. New York: American Foundation for Suicide Prevention; 2018. Available: https://afsp. org/our-work/education/healthcare-professional -burnout-depression-suicide-prevention/ (accessed 2018 May 23).

6. Vogel L. Even resilient doctors report high levels of burnout, finds CMA survey. CMAJ 2018;190:E1293.

7. Zimerschied C. Once endangered, doctors' lounge revived to battle burnout. Chicago: American Medical Association; 2017. Available: www.ama -assn.org/practice-management/physician-health /once-endangered-doctors-lounge-revived-battle -burnout (accessed 2018 May 23).

This article has been peer reviewed.

This is a true story. The Tragically Unfit Mamma's Boys and the family of Bartholomeus Lombard have given their consent for this story to be told.

Author's note: I am very sad to report that as this article was being prepared for publication, another valued colleague, Dr. Stephanus Andreas Van Zyl, died by suicide, leaving behind a young family and good friends. His wife gave consent for me to share this news. 